\title{
Bulk Fill Composites
}

\author{
Alper Kaptan* \\ Department of Restorative Dentistry, Turkey
}

*Corresponding author: Alper Kaptan, Department of Restorative Dentistry, Faculty of Dentistry, Cumhuriyet University, Sivas, Turkey.

Received Date: February 20, 2019

Published Date: March 13, 2019

\begin{abstract}
Resin materials named as bulk fill composite such as low shrinkage stress and their revealing good edge conformity in accordance and their having sufficient radiopacity, their showing sufficient resistance against chewing strengths at posterior region, and their having the feature of being well polished as an aesthetic aspect, have enabled them to be preferred by physicians. The purpose of this review is to give general information about bulk fill composites.
\end{abstract}

\section{Introduction}

Limitation of polymerization depth of composites that are polymerized with light and the requirement to apply them with layers, comes in front of us as an important disadvantage in today's conditions where it is tried to shorten clinical operating time. This thickness has been determined to be maximum $2 \mathrm{~mm}$ by considering penetration depth of light [1]. This situation has caused for processing time at deep cavities to be prolonged and for risk of air bubbles that may occur during the addition of composites to increase. Various producers have produced new type of composites named as bulk fill in order to eliminate this problem [2]. Placement of bulk fill composites as single layer having thickness of 4-5 mm to the cavity regarding deep and wide cavities reduces the period passing at the clinic and it provides significant advantage for dentists [3].

Positive features of resin materials named as bulk fill composite such as low shrinkage stress and their revealing good edge conformity in accordance and their having sufficient radiopacity, their showing sufficient resistance against chewing strengths at posterior region, and their having the feature of being well polished as an aesthetic aspect, have enabled them to be preferred by physicians. Placement of these materials to the cavity is much easier when compared with traditional composites. They're not being polymerized quickly under ambiance light provides sufficient time to physician for the shaping of restoration. Better realization of light penetration in bulk fill composites, occurs by improving translucency features and by means of their including photo- initiators which enable sufficient polymerization depth up to $4 \mathrm{~mm}$ in 10 seconds time. In this way, much deeper polymerization is provided at thicker layers [4-7].

Bulk fill composites are a type of new generation nanohybrid composite resin. While they vary as per the producer companies, they generally contain ytterbium trifluoride, barium glass, mixed oxide, proacrylate, zirconium / silica particles. These particles increase radiopacity and enable for the impact of light device to reach to deeper regions of material. Furthermore, by providing a transparency to composite as being similar to enamel, they also provide aesthetic superiority [8-10].

It has been reported that polymerization takes place slowly due to modified methacrylate resins that are in the structure of bulk fill composites [11]. Nowadays the tendency relating with traditional composite resins is to increase inorganic filler ratio and to reduce the size of fillers in order to ensure better aesthetics [4]. However, while inorganic filler ratio of bulk fill composites is lower when compared with traditional composites in general, size of fillers is bigger. This situation is considered to be a factor that increases polymerization depth. The situation where amounts of inorganic fillers are lower and their dimensions are bigger, enables for total area of fillermatrix intermediary surfaces to be lower. This situation reduces spreading of light and facilitates for it to be penetrated to deeper regions. In bulk fill composites, $\mathrm{CQ}$ has been used as polymerization starter. However, as being different from other bulk fill composites, only in Tetric Evo Ceram Bulk Fill composite in order to increase 
polymerization depth, "Ivocerin" which is a germanium-based initiator has been added to organic matrix in addition to CQ. This new initiator absorbs light better with respect to CQ and it reveals higher photo-polymerization activity [12].

Mechanical features of bulk fill composites vary as per the amount of inorganic filler they contain. For this reason, this type of composite resins is divided into two types as being bulk fill composite resins having low viscosity (being fluid) and bulk fill composites having high viscosity (condensable). During the restoration of cavity, by using bulk fill composites with high viscosity having higher inorganic filler ratio when compared with bulk fill composites with low viscosity, by completely filling in the cavity restoration can be finished. When fluid bulk fill composite resins are used, it is required to finish the restoration by placing a condensable composite resin on the final layer of restoration [2]. Furthermore, fluid bulk fill composites provide ease of use especially at the cavities that can be difficult to reach. Besides, with their high flexibilities and their methacrylate resin contents with urethane base that contain photo-active group, by reducing polymerization shrinkage stress, they can be used as occlusive in occlusal and posterior approximal restorations [13] and they serve as stress blocker [14].

\section{Acknowledgement}

None.

\section{Conflict of Interest}

The authors declare no potential conflicts of interest with respect to the authorship and/or publication of this article.

\section{References}

1. Sakaguchi R, W Douglas, M Peters (1992) Curing light performance and polymerization of composite restorative materials. J Dent 20(3): 183188.
2. Ilie N, S Bucuta, M Draenert (2013) Bulk-fill resin-based composites: an in vitro assessment of their mechanical performance. Oper Dent 38(6): 618-625.

3. Benetti AR, Havndrup-Pedersen C, Honoré D, Pedersen MK, Pallesen U (2015) Bulk-fill resin composites: polymerization contraction, depth of cure, and gap formation. Oper Dent 40(2): 190-200.

4. Czasch P, N Ilie (2013) In vitro comparison of mechanical properties and degree of cure of bulk fill composites. Clin Oral Investig 17(1): 227-235.

5. Fleming GJ, Awan M, Cooper PR, Sloan AJ (2008) The potential of a resincomposite to be cured to a 4mm depth. Dent Mater 24(4): 522-529.

6. Flury S, Hayoz S, Peutzfeldt A, Hüsler J, Lussi A (2012) Depth of cure of resin composites: is the ISO 4049 method suitable for bulk fill materials? Dent Mater 28(5): 521-528.

7. Walter R, Bulk-Fill Flowable Composite Resins. Journal of Esthetic and Restorative Dentistry 25(1): 72-76.

8. Dayangaç B (2000) Composite resin restorations. Güneş Kitabevi.

9. El-Safty S, N Silikas, D Watts (2012) Creep deformation of restorative resin-composites intended for bulk-fill placement. Dental Materials 28(8): 928-935.

10. Lazarchik DA, Hammond BD, Sikes CL, Looney SW, Rueggeberg FA (2007) Hardness comparison of bulk-filled/transtooth and incremental-filled/ occlusally irradiated composite resins. J Prosthet Dent 98(2): 129-140.

11. Moorthy A, Hogg CH, Dowling AH, Grufferty BF, Benetti AR et al. (2012) Cuspal deflection and microleakage in premolar teeth restored with bulk-fill flowable resin-based composite base materials. J Dent 40(6): 500-505.

12. Bucuta S, N Ilie (2014) Light transmittance and micro-mechanical properties of bulk fill vs. conventional resin-based composites. Clin Oral Investig 18(8): 1991-2000.

13. Lassila LV, Nagas E, Vallittu PK, Garoushi S (2012) Translucency of flowable bulk-filling composites of various thicknesses. Chin J Dent Res 15(1): 31-35.

14. Garcia D, Yaman P, Dennison J, Neiva G (2014) Polymerization shrinkage and depth of cure of bulk fill flowable composite resins. Oper Dent 39(4): 441-448. 